\title{
An Overview of The Microgravity Science Glovebox (MSG) Facility, and the Gravity-Dependent Phenomena Research Performed in the MSG on the International Space Station (ISS) \\ Reggie A. Spivey" \\ Tec-Masters Inc., Huntsville, Alabama, 35806
}

William A Sheredy ${ }^{\dagger}$

NASA Glenn Research Center, Cleveland, Ohio, 44135

And

\author{
Ginger Flores ${ }^{\ddagger}$ \\ NASA Marshall Space Flight Center, Huntsville, Alabama, 35812
}

The Microgravity Science Glovebox (MSG) is a double rack facility aboard the International Space Station (ISS) designed for gravity-dependent phenomena investigation handling. The MSG has been operating in the ISS US Laboratory Module since July 2002. The MSG facility provides an enclosed working area for investigation manipulation and observation. The MSG's unique design provides two levels of containment to protect the ISS crew from hazardous operations. Research investigations operating inside the MSG are provided a large 255 liter work volume, 1000 watts of dc power via a versatile supply interface $(120,28, \pm 12$, and $5 \mathrm{Vdc}), 1000$ watts of cooling capability, video and data recording and real time downlink, ground commanding capabilities, access to ISS Vacuum Exhaust and Vacuum Resource Systems, and gaseous nitrogen supply. With these capabilities, the MSG is an ideal platform for research required to advance the technology readiness levels (TRL) needed for the Crew Exploration Vehicle and the Exploration Initiative. Areas of research that will benefit from investigations in the MSG include thermal management, fluid physics, spacecraft fire safety, materials science, combustion, reaction control systems, in situ fabrication and repair, and advanced life support technologies. This paper will provide a detailed explanation of the MSG facility, a synopsis of the research that has already been accomplished in the MSG and an overview of investigations planning to operate in the MSG. In addition, this paper will address possible changes to the MSG utilization process that will be brought about by the transition to ISS as a National Laboratory.

\footnotetext{
" SDOS MSG Project Manager, MSFC ISS Payloads Office, VP35, AlAA Member.

${ }^{\dagger}$ NASA SAME Project Manager, GRC ISS \& Human Research Projects Office, MAHO, AIAA Member

₹ NASA MSG Project Manager, MSFC ISS Payloads Office, VP35, AIAA Member
} 


\section{Introduction}

The Microgravity Science Glovebox (MSG), shown in Fig. 1, is a research facility on-board the International Space Station (ISS) in which fundamental and applied scientific research is conducted that supports NASA's Vision for Space Exploration. The unique design of the facility allows it to accommodate science and technology investigations in a "workbench" type environment. The facility has an enclosed working volume that is held at a negative pressure with respect to the crew living area. This allows the facility to provide two levels of containment for small parts, particulates, fluids, and gasses. The containment provided by the facility reduces the safety requirements placed on the payload developer and facilitates the development of flight hardware in close parallel with prototype or breadboard hardware developed in ground based laboratories. Research investigations operating inside the MSG are provided a large 255 liter work volume, 1000 watts of dc power via a versatile supply interface $(120,28, \pm 12$, and $5 \mathrm{Vdc}), 1000$ watts of cooling capability, video and data recording and real time downlink, ground commanding capabilities, access to ISS Vacuum Exhaust and Vacuum Resource Systems, and gaseous nitrogen supply. With these capabilities, the MSG is an ideal platform for research required to advance the technology readiness levels (TRL) needed for the Crew Exploration Vehicle and the Exploration Initiative. In addition, the facility is ideally suited to provide quick access to space for exploratory type investigations that are necessary to gain an initial understanding of the role of gravity in the physics associated with new research areas.

To facilitate the use of the MSG by the scientific community, an integration team of engineers and support personnel is available at the

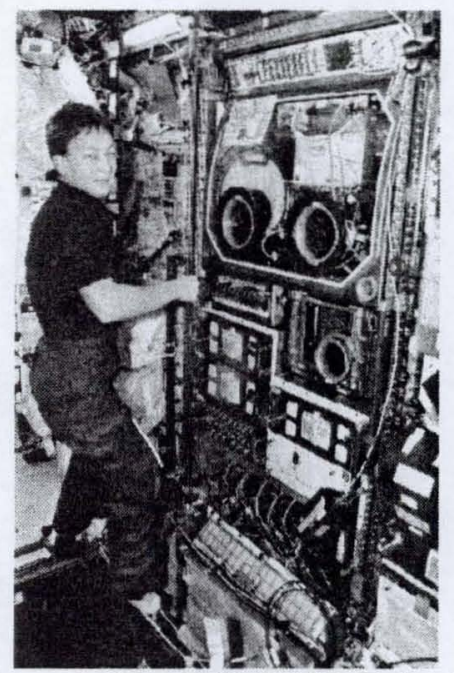

Figure 1. The MSG Flight Unit with Astronaut Peggy Whitson.

Marshall Space Flight Center (MSFC) to assist researchers with the complex task of building and operating an experiment for space. The team advises experiment development groups on engineering issues during the design phase of their investigation, assists with ISS manifesting and planning, and provides support through the testing and analysis activities that are required to assure that experiments are compliant with ISS safety and interface requirements. An engineering unit and development unit is available at MSFC for use during payload development, verification, and on-orbit operation. A high fidelity training unit is located at the Johnson Space Center for training of ISS crew members. Once experiments are transported to the ISS, either by the NASA Shuttle, the Russian Soyuz or Progress vehicles, or the European Space Agency's (ESA) Automated Transfer Vehicle (ATV), the crew installs the experiment hardware in the MSG and configures it for operation. Depending on its design, the actual experiment can be conducted either by the crew or by the ground-based investigator through two-way real-time data links. Experiment progress can be monitored from the ground through the several MSG video cameras, or cameras embedded in the experiment. A telescience center at MSFC provides investigators a link to interact with the experiment during flight operations. The investigator can be located at either MSFC or their home laboratory, where

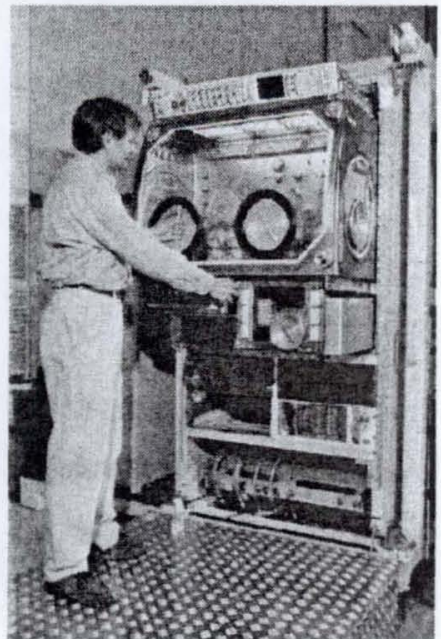

Figure 2. The MSG Rack they are connected via communication links.

\section{Payload Interfaces and Resources Provided by MSG}

The MSG facility is designed to be a versatile platform for space based research. Many of the resources and interfaces found in the MSG are compatible with those typically found in a ground based laboratory. Table 1 provides a summary of the resources provided to experiments inside the MSG facility. The following paragraphs provide a general over view of the MSG capabilities. Additional detail is available on the MSG web site at http://msglovebox.msfc.nasa.gov.

\section{A. The MSG Work Volume}

The MSG work volume, as shown in Fig. 2 \& Fig. 3, provides a large area for set up and operation of experiment hardware. Payloads are loaded into the work volume via the $406 \mathrm{~mm}$ ( $16 \mathrm{in}$.) diameter loading ports 
Table 1. MSG Experiment Resource Summary

\begin{tabular}{|c|c|}
\hline 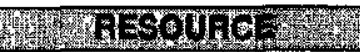 & W \\
\hline POWER & $\begin{array}{l}\text { Three power interfaces are provided in the WV. } \\
\text { - one } 120 \mathrm{~V} \text { DC, } 8.3 \mathrm{Amp} \\
\text { - two } 28 \mathrm{~V} \mathrm{DC} / 7 \mathrm{~A}, \pm 12 \mathrm{~V} \text { DC/2A, } 5 \mathrm{~V} \text { DC/4A } \\
\text { Continuous power allocated to experimenter is a maximum of } 1000 \text { watts. }\end{array}$ \\
\hline DATA & $\begin{array}{l}\text { Eight data interfaces are provide in the WV (two } 1553 \text { for MLC). } \\
\text { - two digital (I/0) and analog input lines } \\
\text { - two RS } 422 \text { serial lines } \\
\text { - one connection to the Ethernet interfaces } \\
\text { - one RS-422/RS } 232 \text { feedthrough from the back wall to the front of the rack for } \\
\text { MLC use outside the WV to an investigation inside the WV } \\
\text { - one user configurable feedthrough at the corner of the front window. }\end{array}$ \\
\hline VIDEO & $\begin{array}{l}\text { - two Sony DSR-V10 DV-CAM digital video recorders ( } 40 \mathrm{~min} / \mathrm{tape}) \\
\text { - two GV-A500 Hi-8 analog video recorders ( } 240 \mathrm{~min} / \mathrm{tape}) \\
\text { - four Hitachi HV-C20 CCD full color cameras } \\
\text { - two multi-input LCD monitors for crew monitoring, }\end{array}$ \\
\hline $\begin{array}{l}\text { EXPERIMENT LAPTOP } \\
\text { COMPUTER }\end{array}$ & $\begin{array}{l}\text { IBM A31p with a } 60 \text { gigabyte hard drive and } 1 \text { gigabyte of RAM. } 1 \text { Ethernet, } 1 \\
\text { RS232/422 (via converter), and USB (via operating system) interfaces. Windows } \\
2000 \text { (Service Pack 4) Operating System. }\end{array}$ \\
\hline STRUCTURAL & $\begin{array}{l}\text { The WV provides for the attachment of hardware either by M6 inserts or bungee } \\
\text { cords. } \\
\text { - Cold Plate: } 24 \mathrm{M} 6 \text { inserts in a } 70 \times 70 \mathrm{~mm} \text { pattern } \\
\text { - Airlock Top Lid: } 18 \mathrm{M} 6 \text { inserts in a } 70 \times 70 \mathrm{~mm} \text { pattern } \\
\text { - Rear Wall: } 20 \mathrm{M} 6 \text { inserts in a } 70 \times 70 \mathrm{~mm} \text { pattern } \\
\text { - Access Ports: } 27 \text { (each) M6 inserts at } 10^{\circ} \text { pitch } \\
\text { - Ceiling: Two locations containing } 8 \mathrm{M} 6 \text { inserts in a } 70 \times 70 \mathrm{~mm} \text { pattern }\end{array}$ \\
\hline THERMAL & $\begin{array}{l}\text { A total of } 1000 \mathrm{~W} \text { can be dissipated from the WV. } \\
\text { - Allowable heat dissipation to the Cold Plate }=800 \mathrm{~W} \\
\text { - Allowable heat dissipation to the Air }=200 \mathrm{~W}\end{array}$ \\
\hline VACUUM & $\begin{array}{l}\text { Two vacuum interfaces are provided in the WV, } \\
\text { - Vacuum resource/venting is provided via a } 1 / 2 \text { " quick disconnect } \\
\text { - Vacuum exhaust/waste is provided via a } 1 / 2 \text { " quick disconnect }\end{array}$ \\
\hline $\mathrm{GN} 2$ & One GN2 interface is provided in the WV via $1 / 4$ " quick disconnect. \\
\hline AIR CIRCULATION & $\begin{array}{l}\text { Max airflow rate of } 1200 \mathrm{l} / \mathrm{min} \text { and a max velocity of } 0.044 \mathrm{~m} / \mathrm{s} \text { at the centerline } \\
\text { of the work volume. } \\
\text { - Airflow can be varied between } 15 \% \text { and } 100 \% \text { depending on fan speed settings. } \\
\text { - Negative pressures of } 13 \mathrm{mB} \text { to at least } 7 \mathrm{mB} \text { based on facility settings. }\end{array}$ \\
\hline AIR FILTERING & $\begin{array}{l}\text { - Three filter banks in series provide WV air filtration. Each bank consists of } 8 \\
\text { HEPA filters in parallel ( } 4 \text { front and } 4 \text { rear). } \\
\text { - Particle filtration down to } 0.3 \text { micron size }\end{array}$ \\
\hline WORK VOLUME (WV) & The WV has an approximate volume of 255 liters. \\
\hline ILLUMINATION & $\begin{array}{l}\text { Adjustable lighting available up to } 1000 \text { Lux incident light measured at the WV } \\
\text { center approximately } 200 \mathrm{~mm} \text { off the WV floor. }\end{array}$ \\
\hline AIRLOCK & $\begin{array}{l}26 \text { liter volume allows access to the WV during operation without compromising } \\
\text { containment. }\end{array}$ \\
\hline
\end{tabular}

on the right and left sides. Hardware can be mounted to the floor, ceiling, back, and/or sides using M6 threaded fasteners. An airlock is provided below the work volume which allows items to be passed into the experiment area without compromising containment. 


\section{B. Electrical Power Interfaces}

The MSG receives, conditions, and distributes electrical power from the ISS Electrical Power System (EPS) to the MSG work volume for use by the investigation. The experiment hardware is provided a maximum of $1000 \mathrm{~W}$ of power. The following primary and secondary supply power interfaces are provided inside the work volume.

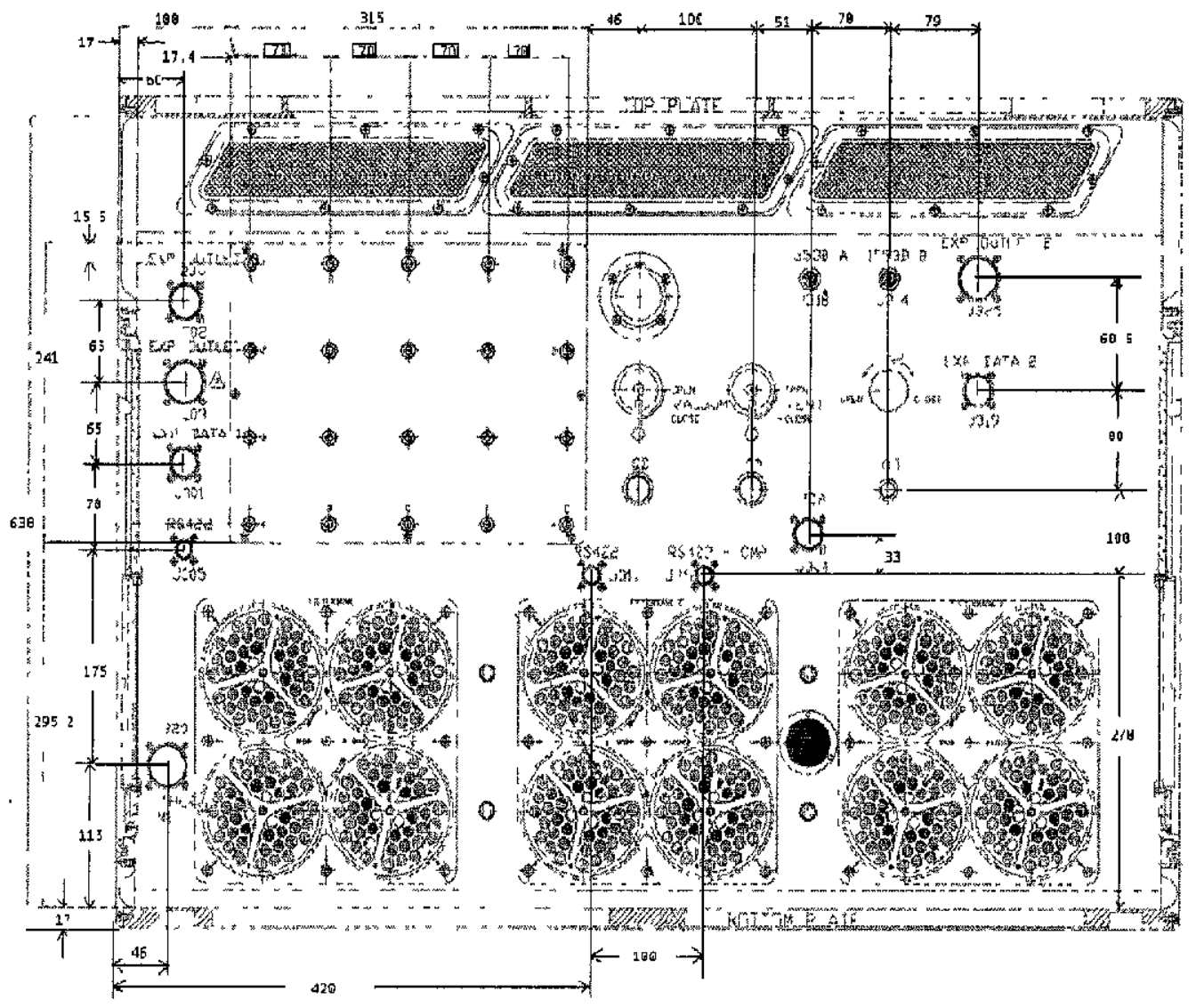

Figure 3. MSG Back Wall Layout.

- Experiment Primary Power

+120 Vdc Power $(120$ Vdc, $8.3 \mathrm{~A})$

- Experiment Secondary Power

$28 \mathrm{Vdc}$ Power, $(+28 \mathrm{Vdc}, 7 \mathrm{~A})$

+12 Vdc Power, $(+12$ Vdc, 2 A)

-12 Vdc Power, (-12 Vdc, 2 A)

5 Vdc Power, $(+5$ Vdc, 8 A)

Secondary power sources are conver ted voltages derived from the DC/DC converters in the MSG Facility. To receive power, experiment hardware must connect to the power supply connectors on the back wall of the work volume shown in Fig. 3. The primary power connector (J302) is supplied on a Mil-Spec type connector MS27656P17F6SA. The experiment must connect to the primary power $(120 \mathrm{Vdc})$ with a Mil-Spec type connector MS27467T17F6PA. Secondary power $(5, \pm 12, \& 28 \mathrm{Vdc})$ connectors $(\mathrm{J} 303 / \mathrm{J} 325)$ are supplied on two MS27656P21F11S connectors in the work volume rear wall as shown in Figure 3. Researchers must connect to secondary power using a connector of type MS27467T21F11P. 


\section{Data Handling}

The MSG data handling system allows for communication with the MSG facility and experiments plus remote operation of the MSG facility and experiments operating inside the WV. The following interfaces are provided to experiment hardware in the work volume; MIL-STD-1553B (via the laptop computer), RS-422 Serial Interface and Digital Input/Output $(\mathrm{I} / \mathrm{O})$ and Analog Input Interface. Investigations are also provided an Ethernet interface that is directly connected to the ISS Ethemet.

\section{Video Systems}

The MSG Video System is provided to observe and record experiment behavior. The MSG Video Drawer consists of the following: four video recorders, multi-input LCD monitors, Hitachi HV-C20 CCD full color cameras, touch-pad, footswitch and a headset/microphone. The video system has the capability to simultaneously record the video signal, display it on the monitors and downlink the video signal to the ground. Experiments that provide their own video cameras must send both Composite and Y/C signals to the MSG video system. The Composite video signal is used to view the camera images on the MSG monitors and for downlinking the video signal. The MSG video recorders require the $\mathrm{Y} / \mathrm{C}$ video signal. Playback is possible on all of the recorders.

There are several ways to operate the video system; it can be commanded from the ground, manually on the recorder itself or by the use of a touch-pad. The video system provides the capability to annotate text onto the video signal and has a time counting system that can be recorded on the video signal and displayed to the operator. The video system has time-lapse capability that allows for extended recording time. The time-lapse settings have two variables that the investigator can choose from, the length of recording and pause period. The range for the length of recording is 0.5 to 25.5 seconds increasing in intervals of $1 / 10$ a second, and the range for the pause period is 5 to 255 seconds in intervals of 1 -second steps.

There are two types of recorders used in the MSG video system: two Sony DSR-V10 DV-CAM digital video recorders with 40 minutes of recording time per digital tape, and two GV-A500 Hi8MM analog recorders with 240 minutes of recording time per tape. Audio can be recorded simultaneously on all four video recorders through the MSG headset/microphone.

\section{E. Thermal Control Interfaces}

The MSG Thermal Control Subsystem (TCS) provides both water cooling and avionics air cooling for experiment hardware. Water cooling is provided by a $350 \mathrm{~mm} \mathrm{x} 400 \mathrm{~mm}$ coldplate embedded in the WV floor. The coldplate is located on the left side of the work volume floor and is capable of dissipating $800 \mathrm{~W}$ under steady state conditions. Experiment hardware is mounted to the coldplate with M6 threaded captive fasteners. Researchers can tighten the fasteners as needed to meet their thermal requirements but they must not exceed 60 in-lbs of torque.

The work volume air circulation is established by the MSG Air Handling Unit (AHU). The AHU heat exchanger provides 200 $W$ of investigation cooling, at an airflow rate of $1200 \mathrm{l} / \mathrm{min}$ and a maximum velocity of 0.044 $\mathrm{m} / \mathrm{s}$ at the centerline of the work volume. The airflow can be varied between $15 \%$ and $100 \%$ depending on fan speed settings. The filtration system provides for particulate removal, filtration of single spillage, and oxidation of $\mathrm{CO}$ to $\mathrm{CO}_{2}$ by means of a built-in catalyst. Due to the hydroscopic nature of the MSG filters, the humidity inside the WV is maintained at or below the ISS cabin level. Fig. 4 provides a block diagram of the MSG air flow.

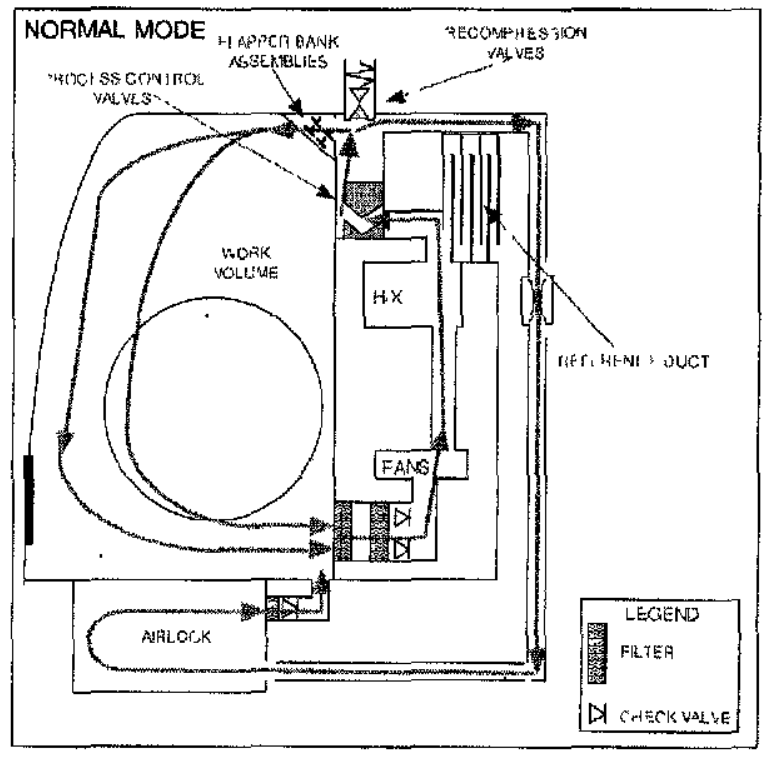

Figure 4. MSG Air Circulation and Filtration. 


\section{F. Experiment Laptop Computer}

The current laptop provided to MSG experiments is an IBM A31p with a 60 gigabyte hard drive and 1 gigabyte of RAM. The laptop supports dual Ethernet, 1 RS232/422 (via converter), and USB (via operating system) interfaces. The operating system is Windows 2000 (Service Pack 4).

Researchers are encouraged to use the server system on the laptop that was developed by the MSG integration team. The laptop server system is a suite of applications that executes on the MSG Laptop Computer. The purpose of the laptop server is to abstract the input/output of the system when experiment applications are running and provide support for various on orbit operations. The laptop server abstracts the 1553B interface, the Serial (RS232/RS422) connections and the Medium Rate Data Link (Ethernet). Instead of each application developer spending the time and effort required to get familiar with each of these interfaces, they may concentrate upon their specific application. The laptop server presents to the applications developer a relatively simple Application Program Interface (API) that uses the basic Windows system function calls. The laptop server provides a consistent interface to each application and allows multiple applications to share information through the defined application interface. The laptop server also provides for extensive ground commanding support (Timelines \& Process Control) to support un-attended operation. All existing interfaces to the laptop have been verified and used in flight so the risk of having communication problems during on-orbit operations is greatly reduced. Researchers can use a simple web based system that allows them to issue commands and display experiment sensor measurements via HTML. By utilizing the FTP server on the laptop, the experiment can take advantage of the laptop hard drive for storage of data that can then be down linked using the ISS Medium Rate Data Link. In addition, the laptop provides a socket based interface to the 1553 data stream for experiment data output.

\section{G. Vacuum Resource/Exhaust and GN2 Subsystem}

The MSG is connected to the ISS Vacuum Resource, ISS Vacuum Exhaust, and GN2 subsystems. The experiment interface to these services is provided inside the WV. The vacuum resource/vent line may be used to operate a furnace or achieve a course vacuum. The vacuum exhaust/waste gas system is used primarily for venting gases or byproducts given off by the experiments. However, the quality of the vacuum at the experiment interface may be lower than the $1 \times 10^{-3}$ torr at the MSG interface due to pressure drops in the ducts, quick disconnects etc. GN2 can be used to inert the internal atmosphere and may provide means for controlling humidity.

The experimenter is provided with quick disconnects at the rear wall of the WV to interface with the vacuum and GN2 resources. The WV is equipped with manually operated ball valves for the vacuum resource and exhaust lines and a needle valve for the GN2 line. There are limitations on the type of gases and materials that can be exhausted into the ISS vacuum system, and the temperature and pressure of the exhaust gases. See the Microgravity Science Glovebox (MSG) Investigation Interface Requirements Document (MSFC-RQMT-2888) for detailed information on connector types and interface requirements concerning the vacuum and GN2 subsystem.

\section{H. Air Circulation and Filtration}

The MSG air circulation and filtration system is illustrated by Fig 4 and Fig. 5. The MSG Air Handling Unit (AHU) has three separate fans that draw air from the WV through the filter banks and blows this air through the water to air heat exchanger, the Process Control Valves and into the Air Discharge Duct, where the air is re-directed towards the WV. These fans maintain the WV pressure lower than the cabin pressure. Any potentially contaminated air can only leave the WV via the reference outlet following filtration. When the MSG is operating in Normal mode, the process control valve is set to allow the air in the WV to be recirculated through the filters, the fans, the heat exchanger, and back into the WV. In this mode the WV will maintain a pressure differential of at least 1.3 mbar between the WV and the outside. When MSG is operating in Sealed mode, the process control valve outlets are sealed off, the fans are off, and no unfiltered air can leave the WV. This mode is also used for experiments not requiring air circulation in the WV.

As shown in Fig. 5, the MSG facility has three filter banks. Each filter bank has a set of four parallel front filters on a front filter plate and a set of four parallel rear filters on a rear filter plate. The rear filters provide a backup filter system. Each front filter consists of four basic elements

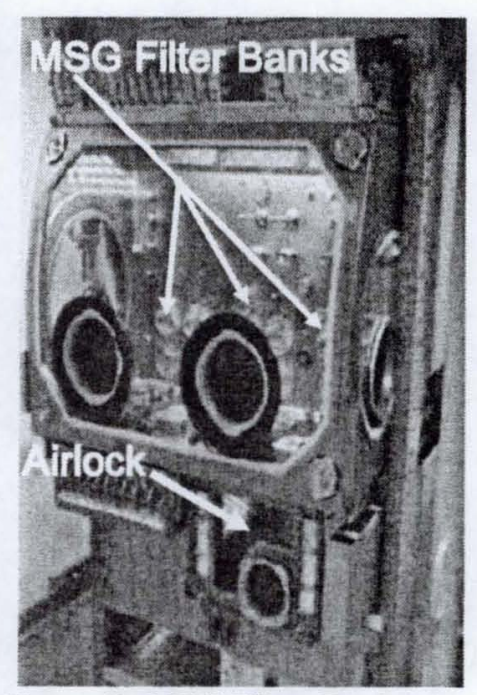

Figure 5. MSG Filter Banks. 
arranged in a specific order. These is a wire mesh which serves as a barrier for flame propagation, High-Efficiency Particle Air (HEPA) filter elements for particle filtration down to 0.3 micron size, an activated carbon element for adsorbing solvents, chemicals and gases, and a monolith element for oxidizing combustion products like carbon monoxide. The rear filter is redundant with the front filter in its ability to filter organic solvents and convert carbon monoxide, there is no HEPA installed in the rear filters. The MSG air circulation system can provide up to $200 \mathrm{~W}$ of cooling.

\section{Illumination}

Three identical illumination units in the top of the WV provide the illumination of the working area. The three illumination units combine to provide 1,000 Lux maximum illumination at approximately $200 \mathrm{~mm}$ above the center of the WV floor. The general illumination is variable in intensity. At the maximum intensity the color temperature is $>2,750 \mathrm{~K}$, with color rendering index (RA) of 85 or better. The Airlock illumination provides 323 Lux general working light. The illumination units can be switched on and off manually by the crew or remotely from the ground.

\section{J. Airlock}

The airlock, shown in Fig. 5, is a box-like structure attached to the bottom plate of the WV with an allowable work area of approximately 26 liters. There is no active thermal conditioning in the airlock. The airlock temperature is ambient, air circulation provides conditioning of the airlock atmosphere only. Airlock illumination can be switched on and off manually or remotely. The airlock front door provides a Lexan Window and a glove port. The front door can be fully removed for ease of loading investigation hardware with the dimensions of $254 \mathrm{~mm}$ (10") by $343 \mathrm{~mm}\left(13.5^{\prime \prime}\right)$ by $299 \mathrm{~mm}\left(11.7^{\prime \prime}\right)$. The Arrlock top lid in the WV contains $18 \mathrm{M6}$ inserts on a $70 \times 70 \mathrm{~mm}$ grid for threaded fastener hardware mounting. The Airlock top lid can be removed completely and can be locked to create a leak tight airlock connection. The topside of the airlock lid is equipped with a removable handle for the actuation of the locking mechanism. When the handle is removed, a complete flat surface is available for use inside the WV. An oven-like concept is used inside the airlock to allow for ease in payload transfer from the airlock to the WV. The concept consists of a tray, which can be placed at two different heights or completely removed from the airlock. The tray is equipped with seven bungee cords for attaching payloads. The filter used in the airlock is the same type as used in the WV. Power is not available for experiments inside the airlock. The temperature and humidity of the Airlock is monitored and is available in the MSG downlink data. Fig. 5 shows the location of the airlock on the bottom right corner of the MSG work volume.

\section{K. Available MSG Facilities}

The MSG project hardware consists of an operational Flight Unit on-board the International Space Station, a high fidelity training unit at the Johnson Space Center (JSC), a ground unit at the Marshall Space Flight Center (MSFC), and a flight equivalent engineering unit at MSFC. The ground unit is functionally equivalent to the flight untt and is available to researchers for development testing and fit checks. The engineering unit is identical to the flight unit and is used to fully verify experiment compatibility prior to flight. In addition, the engineering unit is available for troubleshooting of in-flight anomalies during flight operations. The MSG project also provides researchers with a flight like A3 IP laptop computer as resources allow.

A telescience center at MSFC provides researchers a link to interact with the experiment during flight operations. The investigator can be located at either MSFC or their home laboratory, where they are connected via communication links. The entire communication loop from the telescience center to the payload in the MSG can be simulated using the MSG engineering unit and the telescience facilities at MSFC. This allows for a thorough check out of payload hardware, software, and communication systems prior to flight and affords the researcher a high degree of confidence that the planned experiment will be successful in orbit. 


\section{Overview of the Research Accomplished in the MSG Faclity to Date}

To date, the MSG facility has logged over 3500 hours of on-orbit operations processing 16 investigations. Areas of science that have benefited from experiments in the MSG include, fluid physics, materials science, combustion, thermal control, protein crystal growth, fire detection, and technology demonstration. The paragraphs that follow contain a brief synopses of the investigations that have been performed in the MSG.

\section{A. United States Sponsored Investigations}

\section{Solidification Using a Baffle in Sealed Ampoules (SUBSA) ${ }^{l}$}

One of the first materials science experiments on the International Space Station - the Solidification Using a Baffle in Sealed Ampoules (SUBSA) investigation was conducted during Expedition 5 inside the Microgravity Science Glovebox. SUBSA was the first experiment to operate in the MSG facility on the International Space Station.

The main objective of the SUBSA investigation was to improve science's understanding of the formation of semiconductor crystals. Semiconductor crystals are used for many products such as computer chips, integrated circuits, sensors for medical imaging equipment, and detectors of nuclear radiation.

To control the opto-electronic properties of the semiconductor crystals, a small amount of an impurity - named a dopant - has to be added to the pure semiconductor. Uniform distribution of the dopant in the semiconductor crystal is essential for production of opto-electronic devices.

For the SUBSA investigation, tellurium and zine were used as dopants in an indium antimonide sample. The samples were heated to 850 degrees Celsius and then directionally solidified to form a solid single crystal. The SUBSA samples were loaded in clear quartz ampoules and the SUBSA thermal chamber had a transparent gradient zone which allowed the entire process to be captured on video. Indium antimonide was selected because of its low melting point of around 525 degrees Celsius and because it is useful for creating models that apply to a variety of semiconductors. During processing, the scientist was able to observe the down linked video images and command the furnace from the telescience center at the Marshall Space Flight center to position the solid/liquid interface in the most optimum position prior to the start of directional solidification. This unique capability, provided by the MSG facility, allowed the scientist to optimize the investigation real time, and maximize the scientific return.

The SUBSA investigation was setup on-orbit by Astronaut Perry Whitson and completed operation in October 2002 as part of Expedition 5. The SUBSA investigation was designed and built by Tec-Masters Inc. under contract with the NASA Marshall Space Flight Center in Huntsville, Alabama.

\section{Towards Understanding Pore Formation and Mobility During Controlled Directional Solidification in a Microgravity Environment (PFMI) ${ }^{2}$}

The PFMI investigation sought to improve science's understanding of solidification processes and the effects of imperfections in the molten material. On Earth when scientists melt metals, bubbles that form in the molten material can rise to the surface, pop and disappear. In microgravity, the lighter bubbles do not rise and disappear. Prior space experiments have shown that bubbles often become trapped in the final metal or crystal sample. In the solid, these bubbles, or porosity, are defects that diminish both the material's strength and usefulness.

The Pore Formation and Mobility Investigation melted samples of a transparent modeling material, succinonitrile (SCN) and succinonitrile water mixtures. The transparent material allowed scientists to observe how bubbles form in the samples and study their movements and interactions.

The PFMI experiments heated the SCN samples to approximately 120 degrees Celisus and directionally solidified them at translation velocities of 0.5 micrometers per second up to 10 micrometers per second. Two cameras were used to collect real-time images of the samples as they were melted and subsequently resolidified in the thermal chamber.

Images were sent to the investigator on the ground working in the telescience center at Marshall Space Flight Center. The investigator manipulated the investigation by sending commands to change temperatures, growth rates and other variables that affected sample processing.

The PFMI investigation processed over 20 samples in orbit and was returned on STS-116 in December 2006. The PFMI hardware and software was designed and built by Tec-Masters Inc. under contract with the NASA Marshall Space Flight Center in Huntsville, Alabama. 
Investigating the Structure of Paramagnetic Aggregates from Colloidal Emulsions (InSPACE) ${ }^{3}$

The InSPACE investigation examined the way small magnetic particles interacted with the complex properties found in magnetorheological fluids. Magnetorheological (MR) fluids are a class of "smart " materials capable of providing a rapid, controllable response when a magnetic field is applied. The low-gravity International Space Station environment allowed research on particle interaction without the effects of sedimentation. An objective of the InSPACE investigation was to determine the true threedimensional low-energy structure of a MR emulsion in a pulsed magnetic field. The InSPACE investigation visually studied the final, fine structure of the MR fluid in a pulsed magnetic field. This study helped researchers understand the competing forces that govern the final shape of the structures.

The InSPACE hardware consisted of five major parts: the Helmholtz coil assembly containing the sealed vial that holds the MR fluid; an optics assembly with two long working-distance lenses, cameras, and base plate; an avionics assembly containing two

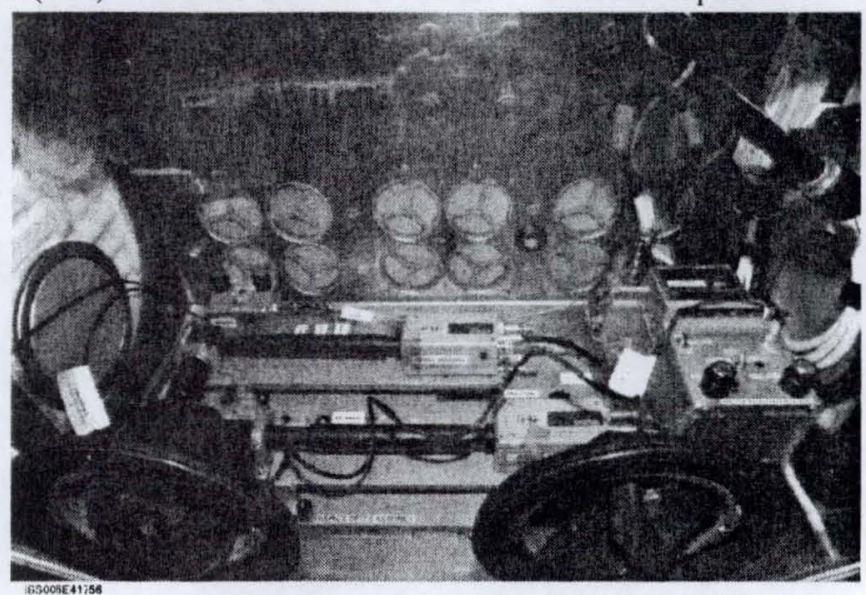

Figure 6. InSPACE Operating in MSG On-Orbit. displays, a square-wave generator, and the power distribution box; the light source assembly; and three video recorders, which are part of the Microgravity Science Glovebox (MSG). The crew inserts the coil assemblies into the optics plate. The square-wave generator then sends pulsed power input along the Helmholtz coil, generating a magnetic field in the fluid. The cameras, equipped with microscopic lenses, record the activities of the fluid microstructures with and without the magnetic field.

The original InSPACE experiments were operated by Astronaut Don Pettit as part of Expedition 6. Two additional coil assemblies and eight sample vials were launched to ISS on STS-120/10A, October 23, 2007. The InSPACE hardware is scheduled to be installed in the MSG in January 2008 and operations will be completed before the MSG is moved to the Columbus Orbiting Facility (COF) in mid February 2008.

\section{Coarsening in Solid Liquid Mixtures-2 (CSLM-2) ${ }^{4}$}

CSLM-2 is a materials science experiment designed to study the rate at which particles of tin suspended in a

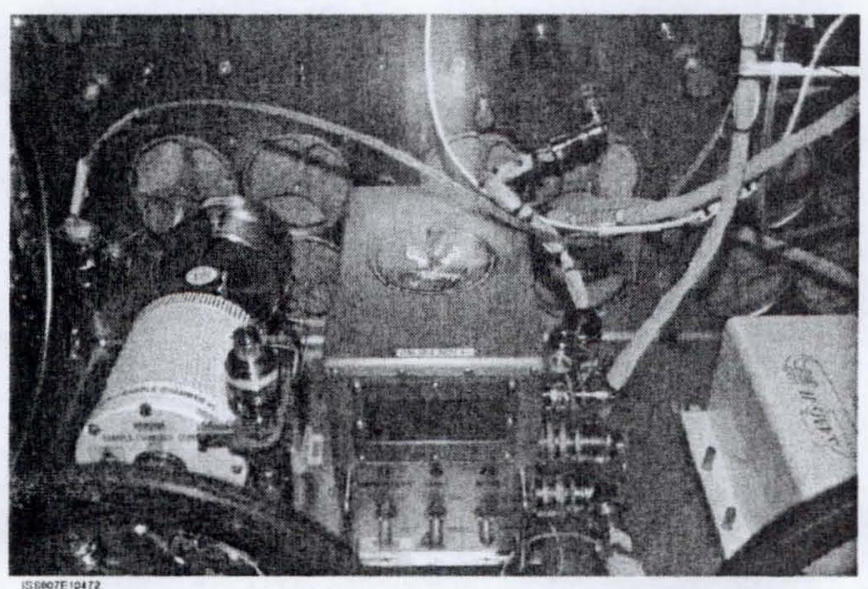

Figure 7. CSLM-2 Setup in MSG Engineering Unit. liquid comprised of molten tin/lead alloy, increase in size, a process called coarsening.

CSLM-2 used the microgravity environment on the ISS to prevent the tin particles from rising to the top of the mixture as well as to eliminate convection in the tin/lead mixture, which can influence coarsening.

In any mixture that contains particles of different sizes, the large particles tend to grow while the smaller particles shrink in a process called coarsening. Tiny oil droplets coalescing into a large blob are one illustration, but the process occurs in solids as well. Coarsening occurs on Earth during the processing of any metal alloy and thus the coarsening process affects products from dental fillings to turbine blades. Since the properties of an alloy are linked to the size of the particles within the solid, coarsening can be used to strengthen materials. This is the case with the majority of aluminum alloys used commercially today. Conversely, if the coarsening process proceeds too long the material can weaken. This occurs in jet turbine blades and is one of the reasons why turbine blades must be replaced after a certain number of hours of service. Thus developing accurate models of the coarsening process is central to creating a wide range of new materials from those used in automobiles to those used in space applications. The results of previous experiments performed on the Shuttle have done just that. These models have been incorporated into a computer code that is being used to design many new materials, 
including materials of importance to NASA's spaceflight program. Solid-liquid systems are ideal systems to study this coarsening process. However, gravity can induce particle sedimentation and thus hamper the studies of coarsening in these mixtures on Earth.

The CSLM-2 Experiment in the MSG consists of an Electronics Control Unit (ECU), Sample Processing Unit (SPU) and associated cables and mounting hardware. The SPU is an evacuated thermal chamber which will heat the samples to $185^{\circ} \mathrm{C}$ for a specified duration. At the conclusion of the heat soak time the samples will be quenched utilizing a pressurized water reservoir. The ECU is a microprocessor based data acquisition and control system designed specifically for conducting the CSLM-2 experiment. The CSLM-2 hardware interfaces to the MSG power, communications, and vacuum resources in support of experiment operations.

Data gathered by the CSLM-2 experiment will advance the development of new high-temperature materials, such as those used in nuclear propulsion and waste heat coolant processes by investigating the kinetics of competitive particle growth within a liquid matrix. During this process, called coarsening, small particles shrink by losing atoms to larger particles causing the larger particles to grow or coarsen. The science team is headed by Professor Peter Voorhees of the Department of Materials Science and Engineering at Northwest University

On August 8, 2007, five CSLM-2 SPUs were launched on the Space Shuttle Endeavour for operations onboard the International Space Station that started November 2007. All five SPUs were processed by December 31, 2007. The SPUs will be returned to the ground on STS-122/1E (Jan 08) and STS-123/1 J/A (Feb 08). The experiment was designed and built by ZIN Technologies Inc under contract with the NASA Glenn Research Center in Cleveland, Ohio.

Smoke Aerosol Measurement Experiment (SAME) ${ }^{5}$

The SAME investigation was developed by the NASA Glenn Research Center, ZIN Technologies, and the National Institute of Standards and Technologies (NIST). The SAME experiment is designed to determine the particle size distributions of the smokes generated from a variety of overheated spacecraft materials and from microgravity fires. The objective is to provide the data that spacecraft designers need to properly design and implement fire detection in spacecraft. This investigation will also evaluate the performance of the smoke detectors currently in use aboard the space shuttle and ISS.

Spacecraft smoke detectors must detect different types of smoke. For example, hydrocarbon fuels typically produce soot and plastics produce droplets of recondensed polymer fragments. While paper and

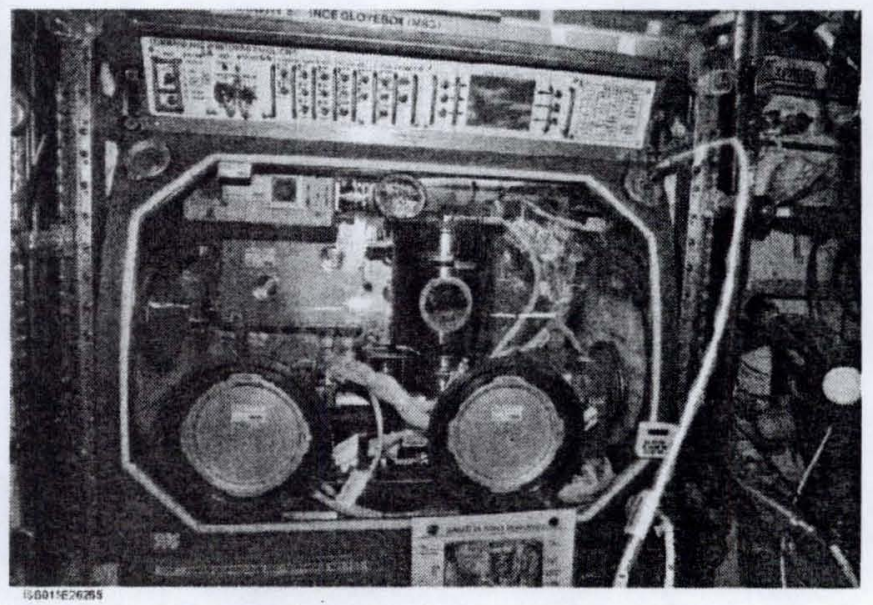

Figure 8. SAME in MSG On-Orbit. silicone rubber produce smoke comprised of liquid droplets of recondensed pyrolysis products. Each of these materials produces a different type of smoke, with particles of various sizes and properties.

SAME will assess the size and distribution of smoke particles produced by different types of material found on spacecraft such as, Teflon, Kapton, cellulose and silicone rubber. SAME will evaluate the performance of the ionization smoke detectors (used on Space Shuttles), evaluate the performance of the photoelectric smoke detectors (used on the ISS) and collect data for which a numerical formula can be developed and used to predict smoke droplet growth and to evaluate alternative smoke detection devices on future spacecraft

The SAME experiment will provide technology for an advanced fire detector for future spacecraft that will be used for long duration missions. SAME will provide quantitative data on the sensitivity of these detectors to reduced gravity smokes that will allow evaluation of the adequacy of these existing technologies using relevant data. The current Fire Prevention, Detection, and Suppression (FPDS) program plan allows for the re-evaluation of future sensor technology, to allow new technology and capability to be utilized. The results from SAME are needed to provide the reduced gravity baseline data against which future detection technology developments can be evaluated. The smoke detectors developed from the results of SAME can also be useful in other extreme environments on Earth, such as submarines or underwater laboratories. The SAME investigation was designed and built by ZIN Technologies Inc. under contract with the NASA Glenn Research Center in Cleveland, Ohio. 


\section{Shear History Extensional Rheology Experiment (SHERE) ${ }^{6}$}

The main objective of SHERE is to study the effect of rotational preshear on the extensional behavior of a fluid. Of specific interest is the transient evolution of the microstructure and viscoelastic tensile stresses that are present during the extension of the fluid.

The combination of both shearing and extensional flows is common in many polymer-processing operations such as extrusion, blow-molding and fiber spinning. Therefore, knowledge of the complete rheological properties of the polymer fluid is required in order to accurately predict and account for its flow behavior. In addition, if numerical simulations are to serve as a priori design tools for optimizing polymer processing operations, then it is critical to have an accurate knowledge of the extensional viscosity and its variation with temperature, concentration, molecular weight, and strain rate.

Unlike common Newtonian fluids, complex fluids such as polymers cannot be characterized by a single material parameter such as the Newtonian (shear) viscosity. Instead, they exhibit nonlinear responses to imposed deformations. The extensional function of non-Newtonian fluids is not constant but depends on both the rate of deformation and the total strain experienced by a fluid element.

A class of dilute polymer solutions, collectively referred to as 'Boger fluids,' has become a popular choice for rheological studies of non-Newtonian fluids and will be used in the SHERE experiment. These ideal elastic fluids exhibit a nearly constant shear viscosity, which allows a direct comparison of Boger fluids with Newtonian fluids having similar viscosities. The high viscosity of the suspending solvent results in long relaxation times and substantial normal stresses, and the low concentration of high molecular weight polymers facilitates modeling analysis.

SHERE is designed to fly in the Microgravity Science Glovebox (MSG) on the International Space Station (ISS). The main SHERE hardware consists of the interface box, rheometer, camera arm, cabling, keyboard. In addition, there are 25 fluid modules in a

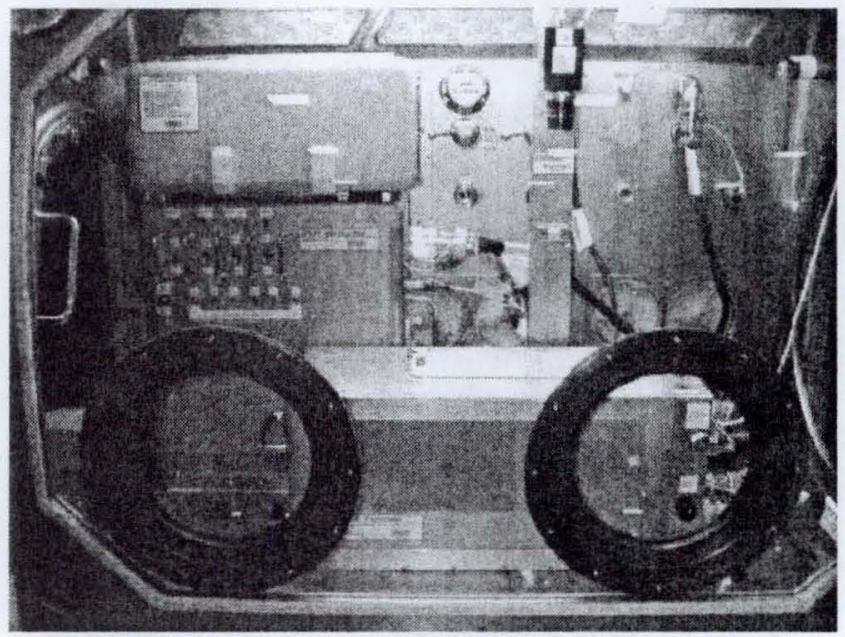

Figure 9. SHERE Setup in MSG Engineering Unit. stowage tray. The interface box contains all power distribution, controllers, and data acquisition and storage. It also contains the video system that combines the camera view and data display onto one video signal for recording and downlink. The rheometer contains the rotational preshear motor, translation slider, sensitive force transducer, electroluminescent backlight panel, laser micrometer, and thermistors. During operation it will also contain one of the 25 fluid modules. The camera arm attaches to rheometer for video recording of the stretched fluid's shape. The tool box contains miscellaneous tools used during setup and operation of the experiment. The keyboard is used to control the experiment with the help of the MSG video monitor. The 25 fluid modules contain the fluid that will be sheared and stretched during the course of the experiment. Each fluid module contains prepackaged Boger fluid, and all samples are identical. Figure 9 shows the SHERE hardware assembled in the MSG Engineering Unit (EU) during integrated testing at the Marshall Space Flight Center (MSFC) in Huntsville, Alabama.

The SHERE experiment hardware was launched to ISS on STS-120/10A, October 23, 2007. Current plans are to launch fluid modules on STS-126/ULF2 (September 2008) and perform the experiments in the MSG during Increment 19 which begins April 2009.

\section{B. European Space Agency Sponsored Investigations}

Since the inception of the MSG program, ESA has developed and operated nine successful investigations in the MSG facility. Four experiments were developed by ESA as part of the Belgian Taxi Flight (BTF). The investigations included COSMIC, DCCO, Nanoslab, and PromISS-1. This series of experiments were a part of the science research activities performed in November 2002 aboard the ISS by Frank de Winne, ESA astronaut of Belgian nationality. Nanoslab encountered technical difficulties and was not able to complete all of the scientific objectives.

In October 2003, Spanish astronaut, Pedro Duque, performed MSG investigations Nanoslab and PromISS-2 as part of the Spanish Soyuz Mission. The Nanoslab investigation was a follow on to the Nanoslab investigation that encountered technical difficulties during the Belgian Taxi Flight. Duque spent eight days aboard the Space Station 
conducting science experiments under a commercial contract between ESA and the Russian Aviation and Space Agency.

In April 2004, MSG investigations HEAT and ARGES were operated as part of the Dutch Soyuz Mission. The experiments were performed by Dutch ESA cosmonaut / astronaut André Kujpers who was launched to ISS from the Russian launch site Baikonur on April 19 $19^{\text {th }}, 2004$.

A thirty day PromISS-3 investigation was performed in January and February of 2004. The same setup was also used during another thirty day PromISS-4 investigation that started in January 2006. Other PromISS investigations are planned for future operations in the MSG. This illustrates the usefulness of the MSG facility. The primary investigation hardware remains on-board and future investigations require relatively little up mass to deliver new samples for follow on experiments.

The following paragraphs provide a brief summary explanation of these ESA investigations. For more detailed information concerning these investigations, please refer to the European Space Agency web page at http://www.esa,int.

\section{Combustion Synthesis under Microgravity Condtions $(\text { COSMIC })^{7}$}

COSMIC studied microstructure formation of compressed powder samples (in casu Ti-A1-B) during selfpropagating high-temperature combustion processes (SHS). The main scientific objective was the investigation of the relationship between general physico-chemical mechanisms of combustion and formation of the microstructure and composition fields. The COSMIC experiment was a part of the science research activities performed aboard the ISS by Frank de Winne, ESA astronaut of Belgian nationality in the frame of the ODISSEA Project. The European Space Agency and Belgian Federal Office for Scientific, Technical and Cultural Affairs (OSTC) were responsible for preparation and implementation of the scientific program.

\section{Microgravity Experiment For the Measurement of Diffusion Coefficients in Crude Oil (DCCO) ${ }^{8}$}

This research program aims to investigate the isothermal diffusion and the Soret effect (thermodiffusion). The scientific communty and petroleum industries have a great interest in the accurate measurements of diffusion and Soret coefficients. The DCCO experiment objective was to measure diffusion coefficients of ternary mixtures of organic compounds. The experimental data set included different liquid mixture mass fractions. The mixtures were composed of n-dodecane, tetrahydronaphthalene and isobutylbenzene that are compounds representative of the crude oil chemical families. The principle was to introduce liquid A into a column of the ternary mixture B by removal of a slider gate. During the three to five hours-expected diffusion duration, the process was monitored with a dual wavelength Mach-Zehnder interferometer, measuring the change in refractive index induced by concentration gradients. From the resulting interferograms recorded on a photo camera, the concentration gradients are derived as a function of time. The DCCO experiment was performed by Belgian astronaut Frank de Winne as part of the Belgian Taxi Flight.

\section{NANOSLAB ${ }^{9}$}

NANOSLAB is physical sciences investigation involving zeolites. Zeolites are crystal formations with structured spaces or pores that allow them to absorb or hold onto other materials such as water. The NANOSLAB research has significance in areas including the petrochemical industry. The aim of this experiment is to try and create more effective zeolite crystal structures by mixing different zeolite solutions with a range of crystal-forming catalysts. The NANOSLAB experiment was conducted by Spanish astronaut Pedro Duque as part of the Spanish Soyuz Mission.

\section{Protein Microscope for the International Space Station (PromISS- 1, 2, 3\& 4) ${ }^{\prime 0}$}

The PromISS investigations are a study of the crystallization of proteins in microgravity conditions. These investigations seek to provide information that will lead to a better understanding of the fundamental processes underlying the protein crystallization process. The major objective of the experiments is to produce a detailed analysis and quantitative interpretation of the relationship between the quality of the crystals and the environment in which they were produced. The objectives are to:

- Further evaluate the effect of microgravity on crystal quality, as compared to experiments in gel.

- Confirm that the removal of convection by the use of gels has a similar effect as microgravity

- Quantify the relationship between position of growth of the crystal and crystal quality. 
The PromiSS investigation uses a Digital Holography Microscope to analyze the crystallization process. The PromISS-1 experiment was performed during the Belgian Taxi Flight in November 2002. Preliminary results obtained show that the instrument was strongly affected by vibrations and the temperature profile of the mission. These factors had a bad impact on the quality of the results obtained.

An upgraded version of the PromlSS-1 hardware, called PROMISS-2 was uploaded with Progress 11P in August 2003 and operated as part of the Spanish Soyuz Mission (SSM). Six PROMISS experiment cells were uploaded with the Soyuz 7S, analyzed with the PROMISS-2 optical diagnostic hardware over 10 days, and downloaded with the Soyuz 6S.

The PromISS- 3 experiment was a re-flight of the previous PromISS- 2 experiment performed during the Spanish Soyuz Mission, but with an investigation of the experimental cells in the Digital Holography Microscope of 30 days. After the 30 day processing, the samples were stowed in an incubator (AQUARIUS) for 2 months, and then returned on Soyuz 8S. The PromISS-3 \& 4 experiments are an adaptation of a digital holography instrument developed by ULB-MRC for the observation of counter-diffusion experiments in microgravity, This instrument provided a view of the crystallization reactions in terms of density gradients in the solution and of the localization of the crystals. The observation of the density gradients should make it possible to evaluate models of the diffusion and residual convection in the crystallization process. This information, together with the localization of the crystals, and the observation of the timing of their growth, can allow the identification of the growth conditions of the crystals. This information can then be related to crystal quality and internal order.

\section{Heat transfer performance of a grooved heat pipe $(\text { Heat })^{h l}$}

Heat was an investigation of the effectiveness of grooved heat pipes in the weightlessness of space. The main aims of this technology demonstration were ;

- The characterization of the heat transfer performance of a grooved heat pipe in weightlessness, by measuring the maximum rate of heat flow sustainable in three different modes:

- Anti-parallel heating/cooling (i.e. heating from one side of the pipe then cooling from opposite side).

- Mixed heating/cooling conditions (i.e. heating from two sides of the pipe then cooling from one of these sides)

- The validation of the existing mathematical model that is used to evaluate the performances of new heat pipes.

- To prove that the grooved heat pipe design can cope with the formation and trapping of vapor bubbles in the pipe. A build up of vapor on the inner surface of a pipe creates an insulating layer, which reduces the pipes effectiveness to transfer heat.

The Heat investigation was performed in April 2004 as part of the Dutch Soyuz Mission.

\section{ARGES Investigation ... Energy efficient lamps for the future ${ }^{2}$}

The ARGES investigation sought to improve the understanding of High-Intensity Discharge (HID) lamps and how they are affected by imperfections. The ARGES experiment examined these HID lamps in the microgravity environment of the International Space Station.

The ceramic container of a HID lamp holds several metal gasses, sealed under high pressure. If a powerful electrical current runs through the gaseous content, the metal atoms in the gas pick up energy and radiate light. However, over time the gaseous contents begin to de-mix or separate away from each other. As a consequence not every part of the lamp has an equivalent amount of energy to transfer into light.

Unstable plasma channels and de-mixed gasses are the two biggest problems in HID lamps. Therefore, the main objectives of the ARGES experiment were to determine which factors were causing these two problems. To do this, the ARGES investigation employed a high-resolution emission spectrometer to analyze a series of individually lighted HID lamps, Each light-producing gas in the HID has its own spectrum. The emission spectrometer was used to determine which gases were present in small areas within the lamp.

Like the Heat investigation, the ARGES investigation was performed in April 2004 as part of the Dutch Soyuz Mission.

\section{Future MSG Investigations}

The many capabilities of the MSG detailed in this paper, make it an ideal platform for research required to advance the technology readiness levels (TRL) needed for the Crew Exploration Vehicle and the Exploration Initiative. Related areas of research that will benefit from investigations in the MSG include combustion, fluids physics, thermal control, fire suppression and detection, in situ fabrication and repair, material science, and life 
sciences. Investigations currently planned for operation in the MSG include BXF, ZBOT, CCF, SPICE, SODI, CWRW, IVGEN, and CETSOL. The following paragraphs provide and brief overview of MSG investigations that are planned for operation in the next two years.

\section{A. Investigations Planned for Near Term Operation in the MSG Facility}

\section{Boiling eXperiment Facility $(\boldsymbol{B X F})^{13}$}

The BXF investigation will obtain data needed to understand the process involved with boiling in gravity and microgravity. The research should enable the development of more efficient cooling systems on future spacecraft and on Earth.

Boiling efficiently removes large amounts of heat by generating vapor from liquid. It is being used in electric power plants, electronic cooling and purification and separation of chemical mixtures. An upper limit, cafled the critical heat flux, exists where the heater is covered with so much vapor that liquid supply to the heater begins to decrease. Supplying constant power above this limit for prolonged periods can increase the heater temperature to the point whereby the heater is destroyed. Determination of critical heat flux in microgravity is essential for designing cooling systems for space. Therefore, boiling is being studied to increase the effectiveness of cooling in space.

The Boiling eXperiment Facility (BXF) will house two separate investigations, BXF-MABE and BXF-NPBX. The purpose of the BXF is to validate models being developed for heat transfer coefficients, critical heat flux and the pool boiling curves. The BXF hardware is scheduled to be transported to ISS in Novernber 2009 by Space Shuttle Endeavour STS-130/19A.

\section{Zero Boil- Off Tank Experiment (ZBOT) ${ }^{14}$}

The ZBOT investigation will improve the scientific understanding of the storage of cryogenic fluids in low gravity conditions. Effective, affordable, and reliable cryogenic fluid storage is essential for propellant and life support systems on interplanetary spacecraft. The Zero-Boil-Off (ZBO) approach is an innovative means of controlling storage tank pressure by eliminating tank self-pressurization through a synergetic application of passive multilayer insulation, an active heat removal system, and a forced mixing mechanism. ZBOT will result in design guides for cryogenic fluid storage tanks and a database of microgravity fluid management data for specitic in-orbit or on surface applications. The end goal is to deliver cost-effective, reliable, and enabling design concepts for longterm storage of cryogenic fluids used in life support and propulsion.

The technology to be developed applies equally to short duration (50-100) day storage applications for the envisioned 2010-2015 missions to the earth's neighborhood and to long duration 100-1000 days interplanetary missions beyond 2015. Consequently ZBOT will encompass both microgravity storage in low and high earth orbit and reduced gravity storage on the lunar, Martian or other planetary surfaces. The ZBOT hardware is scheduled to be transported to ISS in February 2010 by Space Shuttle Discovery STS131/ULF4/.

\section{Critical Velocities in Open Capillary Channels $(C C F)^{15}$}

The CCF Experiment refers to a versatile experiment program for studying an important variety of inertialcapillary dominated flows that are of basic interest in fluid physics and at the same time key to certain space applications, but cannot be studied on the ground. Applications of the results are directed to the portion of the aerospace community challenged by the containment, storage, and handling of large liquid inventories (fuels, cryogens, water) aboard spacecraft. The results are expected to be immediately useful for the design and testing, and instrumentation for verification and validation of liquid management systems of current orbiting, design stage, and advanced spacecraft. The results will also be useful to improved life support system design, phase separation, and enhancing current system reliability by designing into the system passive (in this case 'capillary') redundancies. The CCF hardware is scheduled to be transported to ISS in November 2009 by Space Shuttle Endeavour STS130/19A.

\section{Smoke Point in Coflow Experiment (SPICE) ${ }^{16}$}

The smoke-point phenomena is a classical metric in the understanding of the heat release and spread rate of fires. It is commonly used in 1-g fire modeling and by extension will be of value for predicting the heat release rate of low-gravity fires. The Laminar Soot Processes (LSP) experiment has shown that the onset of the microgravity smoke point in a quiescent environment is very different from that seen in normal gravity. SPICE seeks to extend our understanding by looking at the interaction of ambient flow with the smoke point, enabling us to better predict heat release from low-gravity fires and to better predict their growth rate.

Current NASA spacecraft materials selection is based upon a simplified test method (NASA-STD-6001 Test 1) that segregates material based upon $1 \mathrm{~g}$ behavior without real consideration of low-g effects. lmproved 
understanding of heat release from low-g fires will allow more complete and effective utilization of the results. These results can be used in first-order models and predictions of heat release in spacecraft fires and as a means to extend heat release data from tests like the NASA cone-calorimeter test (NASA-STD-6001 Test 2) to low-gravity fires to a performance based material selection process. SPICE will be flown to the International Space Station (ISS) in January 2009 on Shuttle flight STS-128/17A.

\section{Selectable Optics Diagnostics Instrument (SODI) ${ }^{17}$}

The SODI hardware is being designed by the European Space Agency (ESA) to operate in the MSG facility and accommodate the Diffusion and Soret Coefficients (DSC) measurement investigation, the Influence of Vibration on Diffusion in Liquids (IVIDIL) investigation, and the Aggregation of Colloidal Solutions (COLLOID) investigation. The objective of this series of investigations is to;

- Study diffusion and Soret phenomena and measurement of these coefficients in multi-component mixtures (liquids).

- Study the influence of controlled vibration stimuli on these diffusion processes.

- Study the aggregation (clustering) of colloidal solutions.

The instrumentation will employ several optical diagnostic methods including;

- Mach Zehnder interferometry (MZI)

- Digital Holographic Microscopy (DHM)

- Near Field Scattering (NFS)

- Particle Image Velocimetry (PIV)

- Photogrammetry (PM)

These methods will be used to analyze a selection of liquids and gases in the microgravity environment. The SODI hardware will be transported to ISS on Shuttle flight STS-128/17A and the launch vehicle Japanese HTV1.

Cell Wall/Reverse Genetic Approach to Exploring Genes Responsible for Cell Wall Dynamics in Supporting Tissues of Arabidopsis Under Microgravity Conditions and Resist Wall/Role of Microtubule-Membrane-Cell Wall Continuum in Gravity Resistance in Plants $(C W R W)^{18}$

The Arabidopsis thaliana is considered the ideal model for plant research in the area of genetics and plant
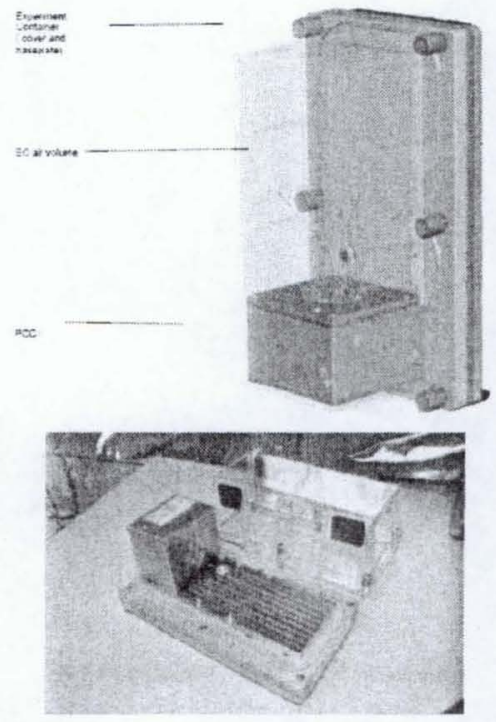

Figure 10. CWRW Hardware. growth. CWRW is an investigation of the Arabidopsis thaliana plant's outer most layer (Cell Wall) genetic composition as it relates to the structural make-up and rigidness of the cell wall. It has been determined from ground experimentation that the structural or physiological continuum of the microtubule plasma membrane cell wall is the source of stability from various gravitational forces. CWRW will investigate the microtubule plasma membrane-cell wall as it relates to the gravitational resistance of the Arabidopsis thaliana.

Observation of the genes that comprise the cell wall of the Arabidopsis will be conducted in $1 \mathrm{~g}$ and microgravity conditions. Upon completion of the investigation, the specimens' stems will be analyzed on the ground for the effects of $1 \mathrm{~g}$ and microgravity conditions. The Arabidopsis thaliana mutates in hyper-gravity conditions with minuet survival capabilities. In microgravity conditions the mutated specimens are expected to gain viability. Proof of this theory will be examined by way of the European Modular Cultivation System (EMCS) internal video recorders, as mutant strains will be developed inside of EMCS. CWRW will examine four strains of Arabidopsis, each of which will be cultivated in the EMCS facility in MSG under controlled conditions. Once the experiment is completed the sample specimens will be evaluated on earth for changes in gene characteristics responsible for the development of microtubules, plasma membrane, cell walls, and relative phenotypes. 
The objective of the CW/RW investigation is to analyze the molecular mechanisms that are responsible for the development of supporting tissues (Cell Wall) in earth plants under induced gravitational forces. Ultimately, the theory that a defined set of cell wall genes contribute to the strength of supporting tissue in plants and that their gene characteristics are manipulated by gravity will be evaluated. The results of these investigations will support future plans to cultivate plants on long-duration exploration missions. CW/RW will be flown to the International Space Station (ISS) on Shuttle flight STS-123/1J/A in February 2008.

\section{IntraVenous Fluids GENeration and mixing (IVGEN $)^{19}$}

With NASA's desire to return to the Moon and to extend manned exploration missions to Mars, there is an increased likelihood of a mishap and/or medical emergency. With a focus on minimizing up-mass for exploration missions, it is desirable to have a system onboard that will produce intravenous (IV) solutions as needed rather than flying large quantities of pre-made IV solutions that have a limited shelf life. IntraVenous fluids GENeration and mixing (IVGEN) is a project whose objective is to design a compact water purification system to reliably produce Sterile Water for Injection (SWI) and provide a pharmaceutical mixing capability in a reduced gravity environment with minimal dependency on spacecraft power resources. IVGEN will be flown to the International Space Station (ISS) on Space Shuttle Endeavour STS-129 (ULF3) currently scheduled for an August 2009 launch.

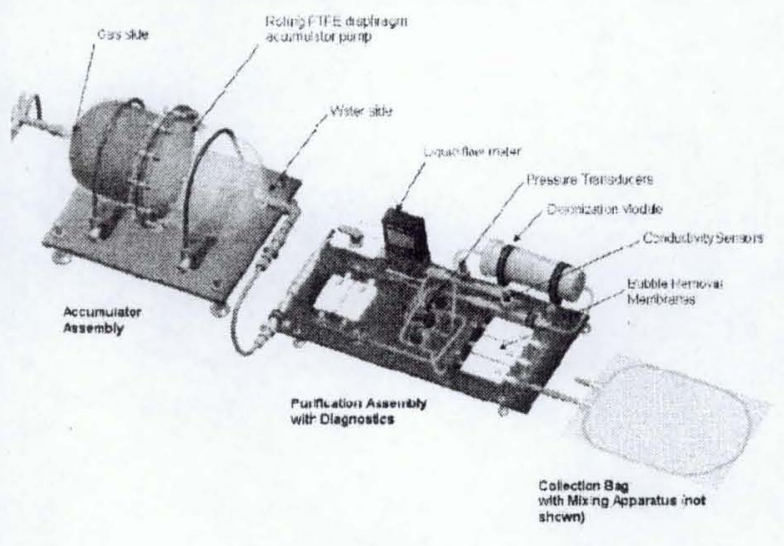

Figure 11. IVGEN Hardware.

\section{Columnar-to-Equiaxed Transition in SOLidification Processes (CETSOL $)^{20}$}

CETSOL is a material science investigation from the European Space Agency (ESA) that will study the formation of the transition from columnar to equiaxed macrostructure that takes place in castings. This experiment will take advantage of the microgravity environment on ISS to gather critical benchmark data needed to test fundamental theories of grain structure formation in solidification processes. The main objective of the investigation is to significantly improve the integrated modeling of grain structure in industrially important castings. The CETSOL investigation hardware will be transported to ISS in January 2009 on Shuttle flight STS-128/17A.

\section{MSG's Role in the International Space Station National Laboratory}

The 2005 NASA Authorization Act designated the U.S segment of the ISS as a national laboratory and directed NASA to develop a plan to "increase the utilization of the ISS by other Federal entities and the private sector..." As the Nation's newest national laboratory, the ISS will further strengthen relationships among NASA, other Federal entities, and private sector leaders in the pursuit of national priorities for the advancement of science, technology, engineering, and mathematics. The ISS National Laboratory will also open new paths for the exploration and economic development of Space.

1. The National Laboratory concept is an opportunity to expand the US economy in space-based research, applications and operations.

2. The International Space Station represents a unique and highly visible national asset with surplus capacity available for a wide spectrum of applications.

3. NASA will continue to cover cost of operating and maintaining the ISS, and is highly motivated to work with other agencies and organizations to pursue applications. ${ }^{21}$ 
When the ISS Facility reaches assembly complete in the year 2010 , over 18 nations will be involved in the program. A major step in completing ISS is the launch of ESA's Columbus Orbiting Facility (COF) in January 2008. The MSG facility will be one of the first US racks moved to the COF in February 2008. The MSG will occupy a US rack location in the COF and will continue to be integrated and operated as a US resource. At this time, significant efforts are underway to streamline the integration process for payloads that want to use the US facilities, including the MSG, on the International Space Station. Most of these efforts center on developing payload categories with standardized sets of resources. In this approach, the manifesting of payloads on the ISS is similar to loading cargo on an airplane. The emphasis is placed on standardizing interfaces and utilizing the majority of the ISS resources with minımal analysis rather than expending an enormous amount of man hours to optimizing all ISS resources. In order to accommodate more payloads, the target integration cycle duration is 6 to 9 months. That is, from the time a payload is manifested on ISS until it is launched will be no more than 6 to 9 months. In order to minimize crew time and crew training requirements, payloads will be designed to be controlled from the ground by the scientist. As described in this paper, the MSG facility has tremendous capability for video observation of payload operation, containment of hazardous materials, data downlink and storage, and remote commanding of payload hardware in the MSG work volume. With these unique capabilities, the MSG facility will be able to accommodate a wide variety of national lab paylaads.

\section{Conclusion}

The Microgravity Science Glovebox (MSG) on the International Space Station (ISS) has been used for a large body of research. The MSG has operated on-orbit for more than 3500 hours performing investigations involving material science, thermal management, protein crystal growth, life sciences, fire detection, combustion, and technology demonstration. The MSG's unique design provides two levels of containment to protect the ISS crew from hazardous operations. Research investigations operating inside the MSG are provided a large 255 liter work volume, 1000 watts of $\mathrm{dc}$ power via a versatile supply interface $(120,28, \pm 12$, and $5 \mathrm{Vdc}), 1000$ watts of cooling capability, video and data recording and real time downlink, ground commanding, access to ISS Vacuum Exhaust and Vacuum Resource Systems, and gaseous nitrogen supply. With these capabilities, the MSG is an ideal platform for space research. Moreover, the MSG provides engineers and scientists a platform for research in an environment similar to the one that spacecrafts and crew members will actually experience during space travel and exploration. In addition, the facility is ideally suited to provide quick, inexpensive access to space for National Lab type investigations that are necessary to understanding of the role of gravity in the physics associated with new research areas. Therefore, the MSG facility is a vital component of NASA's vision for a National Laboratory in Space.

\section{Acknowledgments}

The authors would like to thank the members of the MSG Integration Team for their assistance, and review of this paper. Specifically, Andrew Tygielski, Phillip Bryant, Chris Butler, Jeff Smith, Mark Shelton, and Linda Jeter provided invaluable information and assistance.

\section{References}

\footnotetext{
' A. Ostrogorsky, "Solidffication Using A Baffle in Sealed Ampoules," AIAA-2003-1309, 41st Aerospace Sciences Meeting and Exhibit, Reno, Nevada, Jan. 6-9, 2003

${ }^{2}$ Grugel, R., "Toward Understanding Pore Formation and Mobility During Controlled Directional Solidification in a Microgravity Environment (PFMI)," NASA Marshall Spaceflight Center, Huntsville, AL,

URL: http://exploration.nasa.gov/programs/station/PFMI.html

${ }^{3}$ Gast, A. P., "Investigating the Structure of Paramagnetic Aggregates from Colloidal Emulsions (InSPACE)," Massachusetts Institute of Technology, Cambridge, MA,

URL:http://exploration.nasa.gov/programs/station/InSPACE.html

${ }^{4}$ Voorhees, P., "Coarsening in Solid Liquid Mixtures-2 (CSLM-2)", Northwestern University, Evanston, IL, URL: http://exploration,nasa.gov/programs/station/CSLM-2.html

${ }^{5}$ Urban, D., "Smoke and Aerosol Measurement Experiment (SAME)", Glenn Research Center, Cleveland, OH, URL: http://exploration,nasa.gov/programs/station/SAME.html

${ }^{6}$ Hall, N. and McKinley, G., "Shear History Extensional Rheology Experiment (SHERE)", Glenn Research Center, Cleveland, $\mathrm{OH}$,
} 
URL: http//spaceflightsystems, grc.nasa.gov/Adyanced/ISSResearch/MSG/SHERE/

${ }^{7}$ Froyen, L. "Combustion Synthesis under Microgravity Conditions (COSMIC)," Department MTM, KULeuven, Kasteelpark, Arenberg

${ }^{8}$ Dubois, F, "Microgravity Experiment For the Measurement of Diffusion Coefficients in Crude Oil (DCCO)," Microgravity Research Center, Université Libre de Bruxelles (ULB), Belgium,

URL: http://www.ulb.ac,be/polytech/mre/Instruments_Design/DCCO en,html

${ }^{\&}$ Kirschhook, C., Kremer S., Martens J., \& Pierre J., "NANOSLAB," Centre for Surface Chemistry and Catalysis, K.U. Leuven, URL: http:/www.energia.ru/english/energia/iss/researches/techn-17.html

${ }^{10}$ Zegers, I., \& Dubois F., "Protein Microscope for the International Space Station (PromISS)," Vtije Universitiet, Brussel, Belgium, URL: esamultimedia.esa.int/docs/odissea/promiss_pr 1004.ppt

"Legros, J.C., \& Barremaecker L., Heat, Euro Heat Pipes S.A., Nivelles, Belgium, URL: http://www.esa.int/SPECLALS/Delta_Mission/SEME2H0XDYD 0.html

${ }^{12}$ Kroesen, G.M.W., "ARGES-Energy Efficient Lamps for the Future,", Technical University of Eindhoven, Eindhoven, The Netherlands, URL: http://wwwesa.int/SPECIALSS/Delta_Mission/SEM7RWGHZTD_0 html

${ }^{13}$ Kim, J., "Boiling eXperiment Facility," University of Maryland, College Park, MD,

URL: http://exploration,nasa.gov/programs/station/BXF-MABE.html

${ }^{14}$ Cankaya, A., \& Arnold W., "Microgravity Science Glovebox CFD Model for the Zero Boil-Off Tank

Experiment," AIAA 2006-1336, 44th AIAA Aerospace Sciences Meeting and Exhibit, Reno, Nevada, 9 - 12 January 2006

${ }^{15}$ Dreyer, M., The University of Bremen, Bremen, Germany, and M. Weislogel, M. , Portland State University, Portland, Oregon, Critical Velocities in Open Capillary Channels (CCF)

16 Faeth, G., Smoke Point in Coflow Experiment (SPICE), The University of Michigan, Ann Arbor, Michigan

17 Legros, J.,"Selectable Optics Diagnostics Instrument (SODI)," Microgravity Research Center Université Ljbre de Bruxelles, Belgium, URL http://www.estec,esa.nL/spaceflight/facilities/diffoil/

${ }_{18}$ Kazuhiko, N. and Takayuki, H., "Cell Wall/Reverse Genetic Approach to Exploring Genes Responsible for Cell Wall Dynamics in Supporting Tissues of Arabidopsis Under Microgravity Conditions and Resist Wall/Role of Microtubule-Membrane-Cell Wall Continuum in Gravity Resistance in Plants (CWRW)", Tohoku University, Sendai, Japan.

URL: http://Www.nasa.gov/mission pages/station/science/experiments/CWRW.html

${ }^{19}$ Brown, D., "IntraVenous Fluids GENeration and mixing (IVGEN)", Glenn Research Center, Cleveland, OH,

${ }^{20}$ Gandin, C., Billia, B., Zimmermann, G., Browne, D., Dupouy, M., Guillemat, G., Nguyen-Thi, H., MangelinckNoel, N., Reinhart, G., Sturz, L., McFadden, S., Banaszek, J,, Fautrella, Y., Zaidat K., Ciobanas, A., "Columnar-toEquiaxed Transition in Solidification Processes (CETSOL): a project of the European Space Agency (ESA) Microgravity Applications Promotion (MAP) programme", Materials Science Forum Vol 508 (2006) pp 393-404

${ }^{21}$ B. Boen, "International Space Station Overview;"

URL: http://www.nasa.gov/mission pages/station/science/nlab/index.html 